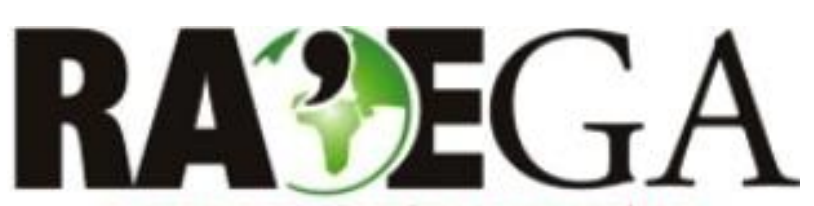

O ESPACYO GEOGRÁFICO EM ANÁLISE

\title{
DA DOMINAÇÃO COLONIAL À COLONIALIDADE DO SABER: EFEITOS DO DETERMINISMO ECOLÓGICO DUAL NO BRASIL
}

\section{FROM COLONIAL DOMINATION TO COLONIALITY OF THE KNOW: EFFECTS OF ECOLOGICAL DETERMINISM DUAL IN THE BRAZIL}

\author{
Sérgio Almeida Loiola \\ Instituto de Estudos Sócio Ambientais - IESA/UFG \\ Universidade Federal de Goiás - UFG \\ Goiânia, GO, Brasil \\ e-mail: sergioaloiola@gmail.com \\ Ludimila Stival Cardoso \\ Uni-Anhanguera: Centro Universitário de Goiás \\ Goiânia, GO, Brasil \\ e-mail: luluscmo@hotmail.com \\ Alexandre Martins Araújo \\ Faculdade de História \\ Universidade Federal de Goiás - UFG \\ Goiânia, GO, Brasil \\ e-mail: araujo.alexandre@uol.com.br \\ Elias Nazareno \\ Faculdade de História \\ Universidade Federal de Goiás - UFG \\ Goiânia, GO, Brasil \\ e-mail: eliasna@hotmail.com
}

\section{Resumo}

Este artigo estabelece reflexões acerca dos efeitos do determinismo ecológico dual sobre a formação social brasileira. Realizada a partir de fontes bibliográficas, a pesquisa funda-se no olhar crítico do pensamento pós-colonial, na semiosis colonial e na perspectiva da interação sociedade-natureza da Historia Ambiental, a fim de desconstruir os signos de dominação disseminados na representação dual da natureza no Brasil. Desde o período colonial a representação de natureza ocorreu numa perspectiva dual: paraíso provedor 
de riquezas, e/ou fator limitante à sociedade; ambas representações tributárias do determinismo ecológico, fundado, sobretudo, na ideia aristotélica dos trópicos como fator limitante às sociedades e na Teoria do degeneracionismo. Esse dualismo originou-se a partir da visão utilitarista e externalizada da relação sociedade-natureza durante o processo de dominação colonial. Influenciou a construção do "ser brasileiro", já que as identidades do povo brasileiro estiveram associadas a noção de selvagem, florestas, meio ecológico e riquezas naturais, operando no modo como o brasileiro se vê, e é visto. Os resultados expõem que, se antes os signos da dominação colonial travestidos de "destino ecológico" eram externos, no presente encontram-se internalizados na mídia, literatura, ciência e na política, oferecendo barreira mental para a identificação das potencialidades e limites do meio ecológico, bem como o desenvolvimento de uma sociedade com elevada sustentabilidade.

Palavras-Chave: representação da natureza; dominação; semiosis colonial; história ambiental; colonialidade

\begin{abstract}
This article contains reflections on the effects of the dual ecological determinism on the Brazilian social formation. Elaborate from literature sources, the research is based on the critical eye of the postcolonial thought, colonial semiosis, as in society-nature perspective of Environmental History, it proposes to deconstruct the foundations of domination in the dual representation of nature in Brazil. Since the colonial period the representation of nature in Brazil occurred in a dual perspective: provider haven of wealth, and/or limiting factor to society; both representations are tributaries of ecological determinism, founded mainly on the Aristotelian idea of the tropics as a limiting factor to societies, and in the Theory of the degeneration. This dualism originated from the utilitarian and externalized view of the society-nature during the process of colonial domination. Influenced the construction of the "Brazilian be", since the identities of the Brazilian people were associated with the notion of wild forests, ecological environment and natural resources, operating in the way the Brazilian sees himself, and is seen. The results explain that, if before the signs of colonial domination disguised as "green destination" were external, in this are internalized in the media, literature, science and politics, offering mental barrier to the identification of the potential and limits of ecological environment, as well as the development of a society with high sustainability.
\end{abstract}

Key words: representation of nature; domination; colonial semiosis; environmental history; coloniality

\title{
1. INTRODUÇÃO
}

Esta terra, Senhor, parece-me que, da ponta que mais contra o sul vimos, até à outra ponta que contra o norte vem, de que nós deste porto houvemos 
LOIOLA, S. A.; CARDOSO, L. S.; ARAÚJO, A. M.; NAZARENO, E.

DA DOMINAÇÃO COLONIAL A COLONIALIDADE DO SABER: EFEITOS DO DETERMINISMO

ECOLÓGICO DUAL SOBRE A FORMAÇÃO SOCIAL BRASILEIRA

\begin{abstract}
vista, será tamanha que haverá nela bem vinte ou vinte e cinco léguas de costa. Traz ao longo do mar em algumas partes grandes barreiras, umas vermelhas, e outras brancas; e a terra de cima toda chã e muito cheia de grandes arvoredos. De ponta a ponta é toda praia... muito chã e muito formosa. Pelo sertão nos pareceu, vista do mar, muito grande; porque a estender olhos, não podíamos ver senão terra e arvoredos - terra que nos parecia muito extensa.

Até agora não pudemos saber se há ouro ou prata nela, ou outra coisa de metal, ou ferro; nem lha vimos. Contudo a terra em si é de muito bons ares frescos e temperados como os de Entre-Douro-e-Minho, porque neste tempo d'agora assim os achávamos como os de lá. Águas são muitas; infinitas. Em tal maneira é graciosa que, querendo-a aproveitar, dar-se-á nela tudo; por causa das águas que tem!

Contudo, o melhor fruto que dela se pode tirar parece-me que será salvar esta gente. E esta deve ser a principal semente que Vossa Alteza em ela deve lançar. E que não houvesse mais do que ter Vossa Alteza aqui esta pousada para essa navegação de Calicute bastava. Quanto mais, disposição para se nela cumprir e fazer o que Vossa Alteza tanto deseja, a saber, acrescentamento da nossa fé! (Trechos da carta de Pero Vaz Caminha enviada ao Rei de Portugal, em maio de 1500, Porto Seguro; In: TEIXEIRA \& PAPÁVERO, 2002, p.73-79).
\end{abstract}

$\mathrm{Na}$ atualidade está em evidência a releitura do processo histórico de formação das sociedades americanas a partir de olhares internos e críticos, sobretudo com o propósito de romper com os laços de dominação colonial. Antes coercitivas e impostas, as premissas da dominação foram assimiladas e internalizadas, atuando de forma subjacentes no meio acadêmico, político e na sociedade em geral como fatores limitantes ao desenvolvimento da ciência, ao estabelecimento de comunidades harmônicas nas suas relações internas, com o ambiente e suas possibilidades.

Ao invés de acumular conhecimentos concebidos nas velhas formas de pensar, essas leituras buscam explorar por novos caminhos o que já se sabe, e o fazem consciente de que falar do mundo é apresentar a si mesmo, já que participam do mundo descrito.

Refletir sobre a formação do "ser brasileiro" no âmbito da dominação tem por fundamento a construção de bases autônomas de pensamento, a partir de diferentes realidades culturais e interesses sociais regionais. Inserido nesse contexto, este trabalho alinha-se com o esforço de produzir bases pensantes próprias, ditas pós-coloniais, ou epistemologias do Sul (SANTOS, 2006, 2009; DUSSEL, 2008). 
LOIOLA, S. A.; CARDOSO, L. S.; ARAÚJO, A. M.; NAZARENO, E.

DA DOMINAÇÃO COLONIAL A COLONIALIDADE DO SABER: EFEITOS DO DETERMINISMO

ECOLÓGICO DUAL SOBRE A FORMAÇÃO SOCIAL BRASILEIRA

Conforme lanne (2002, p.178) o Brasil é "[...] um país, uma sociedade nacional, uma nação ou um Estado-Nação, em busca de conceito". Não faltam, pois, tentativas de interpretá-lo, porém, geralmente desconsidera-se a relação do Brasil e do ser brasileiro com a natureza, ou a influência das ideias acerca da natureza na formação desse ser (LEFF, 2005; ARAÚJO, 2009).

A partir dessas reflexões, esta pesquisa investigou a representação de natureza no Brasil sob a perspectiva da dominação colonial e do determinismo ecológico, a fim de desconstruir os signos de dominação colonial disseminados na representação dual da natureza, no Brasil atual.

Essa ótica operou, e opera, sobre a sociedade numa dupla perspectiva: por uma, a natureza é considerada o paraíso provedor de riquezas; em outra, o ambiente tropical seria um fator limitante à sociedade. Ambas as perspectivas fundam-se em valores modernos e nas falsas premissas do determinismo ecológico, e atuam na forma de pensar, agir, de ver a si e o ambiente, limitando o campo de possibilidades. Ora gera acomodação diante da imagem de paraíso provedor, ora o estranhamento nas relações sociedade-natureza e a degradação ambiental, quando focada a imagem de natureza hostil.

Os laços de dominação colonial coercitivos cederam lugar a internalização da ideia de "destino ecológico", forjados pelas premissas do determinismo ecológico, convertidos numa colonialidade do saber e do poder, em que os povos historicamente subalternizados, em geral povos milenares e negros, e o ambiente continuam a ser explorados internamente pelo Estado Nacional e por uma elite (QUIJANO, 2005, p. 227-278). Desconsiderando a história, importância cultural e os direitos universais desses povos, bem como as características e múltiplas possibilidades ofertadas pelo ambiente, para além do determinismo.

Concebe-se essa relação entre a ideia de natureza e a formação do "ser brasileiro" no contexto de uma sociedade constituída, de um lado, por povos subalternizados, de início, predominantemente por sociedades autóctones, africanos e afrodescendentes escravizados; de outro, a sociedade portuguesa, inferiorizada dentro de outra dita superior: Portugal dentro da Europa 
(SANTOS, 2006). Assim entende-se o Brasil partindo-se da perspectiva de Quijano (2005, p. 02), sob uma dicotomia superioridade/inferioridade, em que "[...] os povos conquistados e dominados foram postos numa situação natural de inferioridade, e consequentemente também seus traços fenotípicos, bem como suas descobertas mentais e culturais".

\section{MATERIAIS E MÉTODOS}

Para tratar dessa problemática utilizou-se uma metodologia comparativa, a partir de fontes bibliográficas, atentos ao que se deseja comparar, por que e como, entendendo que as culturas não são fundamentadas em uma única lógica, que uma mente científica observa, disseca e compara (MIGNOLO, 2009, p.170).

Somos parte do sujeito comparado, pois fazemos parte da língua colonizadora, português, e excluída da ciência moderna durante o processo de colonização. Cabe perceber quais lugares nos foram reservados durante 0 controle e a manipulação colonial. Para tal empreitada recorre-se ao conceito de Semiosis Colonial de Mignolo (2009, p. 175). ${ }^{1}$

Semiosis Colonial é uma expressão usada para sugerir um processo mais que lugares - nos quais "a gente" interatua. Um conceito performativo de interação semiótica que permite ver os encontros coloniais como um processo de controle e manipulação e não transmissão de significado e representação, mudando a perspectiva com que se vê o estabelecimento do Novo Mundo durante o século $\mathrm{XVI}$, concedendo voz à periferia colonial desde onde se percebe o Renascimento Europeu, ou seja, colocando no primeiro plano as "histórias" que os homens europeus negaram a esses "povos", dentro de um panorama de coexistência engendrado por uma luta em nome de poder, dominação e resistência (MIGNOLO, 2009). 
Semiosis Colonial implica a co-presença de interações entre - e de membros de tradições culturais diferentes e a busca por entendê-las, o que conduz a uma perspectiva comparativa entre "[...] lo que se entiende y el acto mismo de entender"2, e permite perceber a coexistência entre as culturas "alta" e "baixa" e as relações de poder de quem controla a economia, a política e as comunidades subalternas. Isto porque a semiosis colonial funda-se em dois axiomas: os diferentes mundos são exuberantes porque dizem mais que se pensa e, os mundos são deficientes porque dizem menos do que se espera.

Através da semiosis colonial a relação do "ser brasileiro" com a natureza irá dizer mais do que pensamos e menos do que esperamos. $O$ estudo nos levará a fazer um pequeno desvio da ciência tradicional, para atravessar as linhas abissais que a ciência moderna ergueu para tornar invisível o "outro lado da linha", já que nessa perspectiva não há possibilidade de coexistência de linhas. Uma só existiria se a outra for declarada inexistente, conforme propôs a ecologia de saberes de Santos (2009). ${ }^{3}$

Considera-se que a abordagem conjunta das noções de semiosis colonial e a travessia das linhas abissais permite desconstruir signos de dominação inseridos na ideia de natureza; pois, o ambiente e a representação da natureza foram retratados sob esses signos, fundados no determinismo ecológico dual, presumindo um linearismo histórico-evolutivo, o qual teve, e tem, forte influência sobre a forma de agir e pensar. A ruptura com a reprodução desses signos requer revisitar o contexto, seu processo de formação e o modo de perpetuação na literatura e na mídia, partindo de um discurso que relacione o tema, a audiência, o contexto de descrição e o locus de enunciação através do qual alguém fala "[...] y hablando, contribuye a

\footnotetext{
2 "o que se entende e o ato mesmo de entender" (tradução dos autores).

${ }^{3} \mathrm{O}$ pensamento moderno ocidental é abissal, realiza distinções visíveis e invisíveis que dividem a realidade social em dois universos diferentes: o universo "deste lado da linha" e o "do outro lado da linha", em que este desaparece como realidade, tornando-se inexistente, ou seja, não pode ser relevante ou compreensível. Assim, prevalece a noção de impossibilidade de existência "do outro lado da linha", na medida em que este lado só prevalece se outro se esgota como realidade relevante (SANTOS, 2009). Isto foi realizado com diversos conhecimentos e povos, entre eles os indígenas e os negros.
} 
cambiar o a mantener sistemas de valores y creencias" ${ }^{4 ”}$ (MIGNOLO, 2009, p. 176).

Para dialogar com a junção entre a cultura e a natureza recorre-se à História Ambiental, a qual enxerga a sociedade e a natureza como indissociáveis, uma interferindo na outra. O ambiente atua sobre a cultura e esta elabora técnicas, normas, políticas e objetivações sobre o espaço e a paisagem (MARTINS, 2007). Para Worster (1991), a História ambiental estrutura-se em três níveis. O primeiro busca entender o funcionamento da natureza, o desenvolvimento dos elementos orgânicos e inorgânicos e suas interações. Já o segundo refere-se à dimensão socioeconômica, à interação entre a organização social e os recursos naturais. E o terceiro nível da história ambiental dedica-se à dimensão simbólica da interação entre homem e natureza e é de grande interesse neste trabalho, já que busca "[...] compreender os tipos de 'negociação' que as diferentes populações estabelecem com o seu meio geográfico, no que se refere aos contínuos processos de apropriação simbólica, adaptação e modificação, ao longo da história" (MARTINS, 2007, p.6).

Por esses pressupostos apresentamos (re)leituras acerca da relação entre a ideia de natureza e o "ser brasileiro", e em que sentido um interfere no outro, ou seja, como o ser vê essa natureza e como esta forma de ver a natureza pode interferir na concepção desse ser sobre si e o meio ecológico.

\section{ÁMERICA LATINA: FRONTEIRA DE FRONTEIRAS ENTRE CIVILIZAÇÕES}

Após cinco séculos do início da formação do povo brasileiro seguramente pode-se afirmar que se trata de um povo etnicamente diverso e culturalmente plural, originado a partir de diferentes civilizações, amalgamadas no continente americano sob a égide da dominação. Conforme Benavides (2011, p. 164), a questão da dominação é um tema predominante na cultura

\footnotetext{
4 "[...] e falando, contribui para mudar ou manter sistemas de valores e crenças" (MIGNOLO, 2009, p. 176).
} 
latino-americana, nas ciências sociais, humanas e outras disciplinas acadêmicas.

Acerca da dominação duas constatações evidenciam-se no Brasil e na América Latina: de um lado, contrariando os defensores da ideologia da mestiçagem, o processo de dominação não homogeneizou as diferenças culturais (LADOUCEUR, 1992; LITTLE, 2002; RATTS, 2003, 1996); de outro, os mecanismos do processo de dominação se internalizaram e transmutaram, estando a serviço da manutenção do poder político, do controle da desigualdade e das minorias étnicas, vistas como ameaças ao ideal de nação (BENAVIDES, 2011, 164-166).

O processo de dominação cristalizou mitos nocivos e limitantes à sociedade e ao convívio com a natureza, entre eles o do determinismo ecológico dual, que ora apresenta a natureza como um paraíso provedor de riquezas inesgotáveis; e ora associa a natureza a um inferno tropical, uma barreira à sociedade. Esses ideários distorcem a realidade, frequentemente conduzem as políticas e os sujeitos à degradação ecológica, ao conflito e a reprodução das desigualdades, por desconhecerem, ou desconsiderarem, o ambiente.

Um campo de distensão socioambiental se perpetua com a reprodução dos signos do determinismo ecológico dual. Essas distensões geraram fronteiras não só no plano visível, como resultaram tanto da intencionalidade de seus atores (LOIOLA e RATTS, 2006), quanto das representações por aqueles que a investigam (HISSA, 2002). Seus motores estão no plano das ideias, crenças, saberes, interesses políticos e culturais, método de pesquisa e do desejo de negação do outro, de modo que os conflitos, dilemas e contradições da fronteira socioespacial são corolários de fronteiras imaginárias, de grande fluidez e abstração.

Representações imaginárias fazem alusões a espaços de referência, o lócus da ação de poder, antecipando a materialização das políticas e criptopolíticas territoriais (SEEMANN, 2003). Assim, o confronto de interesses 
antecede a ação, fazendo com que o território seja um co-produto da apropriação mental e intencionalidades, geralmente ocultas.

\footnotetext{
Produzir uma representação do espaço já é uma apropriação, uma empresa, um controle portanto, mesmo se isto permanece nos limites de um conhecimento. Qualquer projeto no espaço que é expresso por uma representação revela a imagem desejada de um território, de um local de relações. (RAFFESTIN, 1993, p. 144)
}

Ao adentrar o continente, os europeus já continham os pressupostos do confronto. Sob olhar cristão medieval, desqualificaram as culturas, o ambiente, as crenças e o modo de vida dos povos locais (APOLINÁRIO, 2006). Abriram assim caminho à imposição da fé cristã e aos interesses econômicos imediatistas da Coroa, na tentativa de legitimar o saque, a exploração de recursos, o escravismo, a expropriação de terras, as tentativas de re-ocupação e dominação, a serviço da expansão do capitalismo comercial.

No início da colonização, na tentativa de invisibilizar, por vezes, outros povos não eram considerados derivações do gênero humano, a fim de legitimar a exploração violenta, sem ferir a moral cristã: "Sabe-se que, em 1556, quando já se difundia pela Europa cristã a leyenda negra da colonização ibérica, decreta-se na Espanha a proibição oficial do uso das palavras conquistas e conquistadores, que são substituídas por descobrimentos e pobladores, isto é, colonos." (BOSI, 2002, p.12). Termos cujo uso corrente distorce a compreensão do que existia no século XVI: um continente povoado por várias civilizações.

Em sua carta, Caminha elogiou as sociedades encontradas comparando com a pureza de um paraíso: "Eles, porém andam muito bem curados e muito limpos e naquilo me parece ainda mais que são como aves ou animais monteses que lhes faz o ar melhor pena e melhor cabelo que as mansas, porque os corpos seus são tão limpos e tão gordos e tão formosos que não poderia ser melhor [...]”. E prenunciou o que viria: “[...] mas o melhor fruto que nela se pode fazer me parece que é salvar esta gente, e esta deve ser a principal semente que Vossa Alteza nela deve lançar." (TEIXEIRA \& 
PAPÁVERO, 2002, p.73-79). Contudo, a exploração seguiria as intencionalidades originais.

Assim, os ideários do dominador configuraram duas realidades opostas: de um lado, sociedades que se auto-intitulam civilizadas, representadas pelos europeus e, de outro, a suposta "barbárie" advinda dos indígenas e, posteriormente, dos negros, os quais na ótica do colonizador viveriam em Estado de Natureza, por não exibirem as instituições civis encontradas na Europa.

Negros e indígenas foram excluídos da modernidade e ditos nãohumanos, pois estariam engendrados por "[...] práticas incompreensíveis, mágicas ou idolátricas." (SANTOS, 2009, p. 37). Para Giucci (1992, p. 231), sacrifícios humanos feitos aos deuses pelos povos ameríndios, os quais estavam vinculados aos mitos cosmogônicos, "[...] colocava de modo quase automático as noções de selvageria, primitivismo, bestialidade e barbária [...]".

A partir de concepções abissais de epistemologia e legalidade ergueu-se um "[...] vazio jurídico que justificou a invasão e a ocupação dos territórios indígenas sob o binômio apropriação-violência” (SANTOS, 2009, p. 37). No campo do conhecimento, ou epistemológico, foram apropriados saberes sobre a biodiversidade, os caminhos e informações dos guias locais, mitos e cerimônias foram absorvidos para serem manipulados como instrumento de conversão. A violência se reproduziu na proibição das línguas próprias, obrigatoriedade do uso de nomes cristãos, destruição de signos, lugares de culto e a discriminação cultural e racial.

No campo da legalidade, ou do direito, a apropriação e a violência evidenciaram-se no tráfico de pessoas, trabalho forçado, manipulação do governo local, estabelecimento de governo indireto, pilhagem de recursos naturais, deslocamento das populações, guerras e tratados desiguais, apartheids e assimilação forçada, entre outros. Desta forma, se houve, no início, um encontro de culturas, as intencionalidades sob o binômio apropriação-violência levariam ao confronto, à invasão e à (re)ocupação do território. 
Para Bosi (2002, p. 26), no processo de dominação estabeleceu-se uma dialética do culto e da cultura, impondo uma condição colonial. Termos brandos de assimilação, de Gilberto Freyre, e processo de feliz aclimação e solidariedade cultural, de Sérgio B. de Holanda, encobrem os significados da condição colonial, que antes de ser feliz assimilação solidária era falocrática.

A condição colonial implica relações interpessoal e subjetiva, a memória e o sonho, as marcas do cotidiano no coração e na mente, o modo de nascer, de comer, de morar, de dormir, de amar, de chorar, de rezar, de cantar, de morrer e ser sepultado. Sob essas condições o colono se apropriou dos bens materiais e culturais do negro e do indígena.

A leyenda negra evidenciou não somente desdobramento de uma fronteira territorial e mental, mas a negação intencional dos "outros" do outro lado da fronteira e das linhas abissais, fundadas em ideários eurocêntricos, um ego conquiro moderno (DUSSEL, 2008, p.179), a serviço da dominação colonial moderna. Essa dominação esteve presente nas relações humanas e nas relações sociedade-natureza. Linhas abissais imaginárias separavam o mundo dito civilizado e o dito não civilizado igualmente no meio ecológico.

\section{DA FRONTEIRA CULTURAL À DEMONIZAÇÃO DO AMBIENTE}

Durante o século $X \mathrm{VI}$, paralelo às ideias de mundo exuberante, o pensamento mágico português renascentista retratou a floresta tropical como impenetrável, povoada por bestas feras monstruosas (PRESTES, 2000, p. 33). Sob olhar empírico e mágico antropocêntrico europeu, os portugueses olharam para a natureza tropical tentando encontrar similitudes com o que havia em seu continente, desprezando o que se apresentava como diferente, ou exótico.

$O$ reduzido interesse em observar e documentar a rica fauna e flora evidencia o desprezo pelas paisagens naturais e seus habitantes. Para Dean (1996, p.100), talvez os portugueses aceitassem mais as informações de sábios indianos e chineses vestidos de seda do que de pajés tupis botanicamente experientes, mas nus e iletrados. Nesse sentido, o estranhamento não se deu somente no plano cultural. Referenciadas em 
paisagens e climas temperados, as descrições do ambiente tropical também oscilaram entre paraíso e inferno.

\begin{abstract}
Em parte, a ideia de "inferno verde" decorreu do etnocentrismo europeu em relação aos diferentes meios de vida nos ambientes tropicais. Por muito tempo os cientistas guiaram-se pelo senso comum, considerando as economias indígenas como pobres ou atrasadas, em vez de considerá-las apenas diferentes da sua economia capitalista e urbana (FUNARI e NOELLI, 2002, p.31).
\end{abstract}

É provável que esse paradoxo tenha se sustentado na afirmativa aristotélica de inviabilidade da vida nos trópicos. Até o século XIX a evidência empírica oferecida pela diversidade biológica nos trópicos não teria sido fortalecida por um corpo teórico que apagasse de vez essa noção aristotélica (PRESTES, 2000, p. 127), pois predominava ainda a ideia de inadequabilidade tropical ao ser humano, reproduzidas nos discursos dos naturalistas. Em 1847, no seu relatório Viagem a Província de Goiás, Saint-Hilaire considerou as sociedades autóctones selvagens e a vegetação, embora tida como exuberante, foi dita inútil:

\begin{abstract}
Se alguns exemplares dos meus relatos resistirem ao tempo e ao esquecimento, as gerações futuras talvez encontrem neles informações de grande interesse sobre essas vastas províncias, provavelmente transformadas, então, em verdadeiros impérios. E ficarão surpreendidas ao verificarem que, nos locais onde se erguerão então cidades prósperas e populosas, havia outrora apenas um ou dois casebres que pouco diferentes das choças dos selvagens; [...]; que, em lugar das extensas plantações de milho, de mandioca, de cana-de-açúcar, e de arvores frutíferas, o que havia eram terras cobertas por uma vegetação exuberante, mas inútil. ${ }^{5}$ (SAINTHILAIRE, 1975, p. 14)
\end{abstract}

As ideias aristotélicas de inadequabilidade tropical deram suporte à teoria do degeneracionismo, difundida entre diversos pensadores europeus, os quais consideravam os trópicos desfavoráveis à humanidade. Por essa teoria, o clima quente e úmido das florestas induziria ao desordenamento sexual, criação de etnias e línguas, degeneração cultural e moral, levando à extinção. O ser humano foi reduzido a um subproduto ambiental: "Também podemos observar que, se as teorias explicativas encontram-se sempre imbricadas na

\footnotetext{
${ }^{5}$ Grifo nosso.
} 
sociedade que as origina, está claro que o determinismo ambiental insere-se em certa visão de mundo colonialista." (FUNARI e NOELLI, 2002,p.52).

Representante da teoria do degeneracionismo, em 1845, Von Martius publicou um ensaio "Como se deve escrever a História do Brasil", e venceu um concurso do Instituto Histórico e Geográfico Brasileiro (IHGB). Sob premissas da teoria determinista, Martius influenciou intelectuais no Brasil, cujo alcance perdura até os dias atuais. Os seguidores atuaram, sobretudo em instituições como a FUNAI, pressupondo que haveria uma homogeneização dos grupos étnicos e línguas no Brasil em torno de uma única civilização e língua, a civilização brasileira.

A obra intitulada Hand book of South American Indians (1963), organizada por Julian Steward reproduziu essas ideias deterministas ao estabelecer hierarquia entre culturas Andinas, ditas desenvolvidas, dada a existência de Estado, e as culturas das terras baixas da América do Sul (FUNARI e NOELLI, 2002). Na arqueologia, Betty Meggers seguiu Stewart. Em América Pré-histórica (1979), Meggers deixa entrever sua visão ao atribuir o desenvolvimento dos Estados Unidos da América e o subdesenvolvimento da América Latina às condições geográficas:

\footnotetext{
Considere-se a diferença entre os limites dessas áreas ecológicas e os das nações modernas. Na América do Norte, os Estado Unidos estendem-se de oceano a oceano, por florestas, campos e desertos. Na América do Sul, em contraposição, as modernas divisões coincidem mais de perto com as zonas ecológicas. O Brasil é principalmente florestas; a Argentina, campo; o Chile, costa do Pacifico; Colômbia e Venezuela são zonas intermediárias. Essa diferença é significativa. Se a América do Norte tivesse sido desmembrada em muitos países, um ocupando a floresta, outro os campos, outro o deserto e outro a costa do Pacífico, a situação seria comparável à da América do Sul e os problemas de desenvolvimento seriam provavelmente análogos. (apud FUNARI e NOELLI, 2002, p.52)
}

Este pensamento demonstra as limitações de intelectuais que tentam justificar a dominação pelo determinismo ecológico, e as limitações induzidas na sociedade, já que essa perspectiva leva a interpretações equivocadas acerca da teoria da evolução, ao supor que tendências evolutivas podem ser preditas (GONÇALVES, 2002; LORENZ, 1986; CAPRA, 2001). Conforme Souza (1997), por teorias derivadas, o determinismo induziu formas enganosas 
de pensar o desenvolvimento por etapas obrigatórias e universais, referenciadas nas histórias dos países do norte, de climas temperados, outros ambientes, culturas e interesses.

Relatos de naturalistas, no século XIX, alimentaram os equívocos acerca do ambiente tropical e a cultura dos povos tradicionais, por vezes gerando observações ora simplificadoras, ora deformadoras da realidade (DOLES e NUNES, 1992, p. 83). A perspectiva aristotélica e do determinismo ecológico foram difundidas nos relatos, e dificultaram a compreensão das outras possibilidades históricas, como a formação socioespacial da terra brasilis. ${ }^{6}$

Tal construção semântica influenciou a ideia de nação, em que a natureza ressurge com as viagens ao sertão. Este, ora visto como inóspito, cheio de doenças e povos sertanejos preguiçosos; ora percebido como representação do nacional, pela presença do "natural" e pela íntima relação com o sertanejo, considerado forte e bravo. Essa polarização, entre paraíso provedor e inferno verde, se propagou na academia, na literatura e no mundo midiático, tornando-se um elemento mental coletivo relevante a ser compreendido, e desconstruído.

\section{ENTRE O CÉUE O INFERNOECOLÓGICO}

A percepção e a representação da natureza variam de acordo com a cultura, já que esta "[...] é como uma lente através da qual o homem vê o mundo.". Consequentemente, "[...] homens de culturas diferentes usam lentes diversas e, portanto, têm visões desencontradas das coisas." (LARAIA, 2002, p. 67). Desta forma, a noção de natureza varia de uma sociedade à outra, sendo específica e condizente com artefatos, princípios e pressupostos culturais, significando que o "ser" da "natureza" se modifica e continua sendo re-significado (ARAÚJO, 2009, p. 7).

\footnotetext{
${ }^{6}$ Caracterizada por domínio territorial e laços de poder horizontalizados tanto na gestão, organização quanto na defesa; divisão social do trabalho, modo de produzir e viver voltados a auto-suficiência, de base agrária, associados a valores culturais de não- acumulação; pouca concentração de poder e hierarquia; flexibilidade e laços socioculturais no plano interno e externo com grupos de diferentes etnias, línguas e bases econômicas. Ver Prous (2006), Guidon (2003; 2005) e Loiola, 2007.
} 
Essa mudança, de significação da natureza, verifica-se na história do continente americano e do Brasil. No início, a natureza foi idealizada como um paraíso perdido, tal qual descrevera Cristovão Colombo quando chegara à América (TODOROV, 1983, p. 17), uma vez que o Paraíso Terrestre estaria localizado numa região temperada além do Equador, denominado América, que ele acabara de descobrir, ou encontrar.

Prevalecia nesse período a ideia de natureza exuberante e inesgotável, como narrou Caminha em sua carta: "Em tal maneira é graciosa que, querendo-a aproveitar, dar-se-á nela tudo; por causa das águas que tem!". No período colonial, o Brasil passou a ser sondado por vários exploradores, objetivando confirmar em seus mais recônditos locais "estranhezas agrestes" que muito perturbaram os imaginários desses homens medievais (ARAÚJO, 2009).

No período imperial, do Brasil independente, a relação do país com a natureza foi, em muito, moldada pela atuação do IHGB, criado em $1838 \mathrm{com}$ o objetivo de "[...] pensar o Brasil segundo os postulados próprios de uma história comprometida com o desvendamento do processo de gênese da Nação." (GUIMARÃES, 1988, p. 6).

Tentativa complexa, pois envolvia construir um projeto nacional "[...] para uma sociedade marcada pelo trabalho escravo e pela existência de populações indígenas." (idem) por meio de ideias iluministas de nação homogênea, estabelecidas entre as elites. Sob ideias do velho Mundo, o IHGB subsidiaria a construção da nação excluindo todos os que não eram portadores dessas ideias: indígenas e afrodescendentes, ou seja, a Nação brasileira aparece como um desdobramento da civilização branca e europeia.

Tal projeto se formulou a partir da concepção iluminista de história: linear e marcada pela perspectiva do progresso. Pesquisadores do IHGB passaram a utilizar conhecimentos arqueológicos, linguísticos e etnográficos na argumentação científica para acessar as culturas indígenas, na tentativa de demonstrar sua inferioridade diante da "civilização branca" (GUIMARÃES, 1988). A civilização branca caberia o papel de civilizadora e a construção de 
LOIOLA, S. A.; CARDOSO, L. S.; ARAÚJO, A. M.; NAZARENO, E.

DA DOMINAÇÃO COLONIAL A COLONIALIDADE DO SABER: EFEITOS DO DETERMINISMO

ECOLÓGICO DUAL SOBRE A FORMAÇÃO SOCIAL BRASILEIRA

uma nação miscigenada com os indígenas e os negros, erguendo assim o mito de democracia racial.

Desta forma, a Revista trimestral do IHGB se ocupou com temas como: a problemática indígena, as viagens e explorações científicas e a história regional, no sentido de entender a melhor maneira de "colonizar os índios", a fim com o projeto de integração nacional (GUIMARÃES, 1988). Este projeto buscava definir os contornos físicos do país, sob prerrogativas de continentalidade e inúmeras riquezas, na tentativa de realizar sua identidade e considerar as regiões como organicamente presentes no conjunto nacional.

As viagens e as explorações científicas se propuseram a descrever as paisagens e catalogar diversas espécies de plantas e animais para construir cartografias do Brasil, em que "[...] a natureza se configura na tensão entre imagens paradisíacas e infernais - tensão essa que se dinamiza na oposição entre civilização e natureza e suas noções derivadas, domesticação e selvageria." (LISBOA, 1997, p. 429), tal qual a perspectiva do IHGB, pois, para este Instituto, a Nação brasileira viveria sob a tensão de um lado de indígenas e afrodescendentes, representando a natureza e a selvageria; e de outro, os brancos, a civilização, e a domesticação.

No final do século XIX e início do XX, no contexto da abolição da escravatura e da instituição da República, teve início a formação de uma intelligentsia com o objetivo de interpretar o Brasil, pensado por meio da noção de atraso histórico, dividido, por um lado, entre os intelectuais de camadas econômica e politicamente dominantes, e das classes médias urbanas. Por outro, os despossuídos e oprimidos, da qual a elite intelectual fala como que desterrada na própria terra (LIMA, 1999), já que fala de uma sociedade em que não se sente presente, mesmo sendo uma intelligentsia nacional.

Assim, a elite intelectual discorria sobre uma realidade na qual não se reconhecia. Ela construía a ideia de "ser brasileiro" do qual pensava não ser parte, levando Euclides da Cunha a considerá-la "imbecilidade triunfante".

Buscava-se construir um pensamento que consolidasse o Estado como construtor da nação em um Brasil dual, parte progressista, mas copista de 
LOIOLA, S. A.; CARDOSO, L. S.; ARAÚJO, A. M.; NAZARENO, E.

DA DOMINAÇÃO COLONIAL A COLONIALIDADE DO SABER: EFEITOS DO DETERMINISMO

ECOLÓGICO DUAL SOBRE A FORMAÇÃO SOCIAL BRASILEIRA

sociedades europeias (CARVALHO, 1990); e parte atrasada e isolada, que poderia ser o cerne da nacionalidade, em que o sertanejo aparece como uma possibilidade de caracterizar os tipos brasileiros, elevando a natureza ao status de sujeito histórico.

Nesse contexto, o sertão aparece relacionado aos elementos naturais e à simbiose com o homem sertanejo, além de coadunar com a noção de resistência ao moderno por estar, também, fortemente ligado à ideia de raça, utilizada para inferiorizar sociedades, que foram ditas "naturalmente inferiores".

Essa perspectiva presa ao atraso produziu um pensamento que viu o sertão como a "[...] possibilidade do desenvolvimento de uma autêntica consciência nacional." (LIMA, 1999, p, 61), vinculando a nacionalidade ao binômio Humano-Natureza, representado na obra Os sertões, publicado em 1902, de Euclídes da Cunha, visto que no livro, Canudos, o sertão é caracterizado "[...] pela supremacia da natureza sobre o homem, pela quase impenetrabilidade da caatinga e pela autenticidade da nação." (p. 68), não excluindo a representação negativa do sertanejo e, a um só tempo, incentivando a "civilização do litoral" a viajar ao sertão para agregá-lo ao Estado brasileiro.

O Brasil, por esse pensamento, viveria em situação ambivalente, com um tipo nacional, o sertanejo, que resultaria da mestiçagem e, em decorrência disso, uma nacionalidade construída com base na relação entre homem e ambiente, posto que há nesse 'brasileiro' uma “[...] completa adaptação às condições ecológicas: ele é um forte; representa um verdadeiro tipo de raça brasileira." (ROQUETTE-PINTO, 1927, p. 296).

As representações do tipo nacional, entretanto, variaram ao longo da história: de autêntico e forte até um retrato satírico do homem do interior. ${ }^{7} \mathrm{De}$ um lado tem-se a obra $O$ sertanejo, de José de Alencar, publicada em 1875, em que, segundo Lima (1999), seu homem-título se caracteriza pela altivez e o domínio da natureza e; de outro o Jeca-Tatu, da obra Urupês, de Monteiro

\footnotetext{
${ }^{7}$ Tipo nacional: o sertanejo, o caipira, o homem do interior do país.
} 
Lobato, publicada em 1918, imagem de preguiça, indolência, imprevidência. "Piolho da terra" e parasita associado à destruição da mata em nome da agricultura primitiva, assim como o concebe, em alguns momentos, Euclides da Cunha.

O Jeca-Tatu foi associado ao riso, como forma de representar uma oposição à excentricidade e rigidez mecânica do corpo social. Mais que função estética, $\mathrm{o}$ ato de rir evitaria o isolamento e daria flexibilidade, já que pode ser uma atividade humana com função social de aperfeiçoamento, conforme pensara Bergson:

[...] o riso reprime as excentricidades, mantém constantemente vigilantes e em contato recíproco certas atividades de ordem acessória que correriam o risco de isolar-se e adormecer; flexibiliza enfim tudo o que pode restar de rigidez mecânica na superfície do corpo social. O riso, portanto, não é da alçada da estética pura, pois persegue (de modo inconsciente e até imoral em muitos casos particulares) um objetivo útil de aperfeiçoamento geral (BERGSON, 2001, p. 15).

Para Bergson (2001), portanto, "[...] o riso 'castiga os costumes. Ele nos faz tentar imediatamente parecer o que deveríamos ser o que sem dúvida acabaremos um dia por ser de verdade." (p. 13), ou seja, o riso desencadeia-se pela quebra da rigidez mecânica que está sobreposta ao vivo. Teria a prerrogativa de sansão funcional em relação ao desvio que representa 0 cômico (ALBERTI, 2002). O riso passa a funcionar como meio para se restabelecer o vivo na sociedade, sem o qual não se consegue viver coletivamente.

O riso acabaria representando uma maneira de punir os desvios e garantir a homogeneidade e funcionamento do social, o que vai ao encontro da construção satírica de Monteiro Lobato, pois a risada que o Jeca provoca se perfaz em rir da tragédia que seria a vida de um caipira ou um sertanejo no meio ecológico supostamente adverso. Ri-se, pois, daquilo que degrada nossa imagem de "brasileiros". Pune-se o "caipira" como um desvio da "civilização branca" e, simultaneamente, controla-se a sociedade, já que permitiria a existência desse "outro", mas o impedindo, mesmo que temporariamente, de colocar-se contrário à estrutura social. 
A relação entre homem e ambiente construída a partir de Monteiro Lobato, com seu Jeca-Tatu, promove a degradação do caipira/sertanejo, muitas vezes não percebida pelo riso que libera, mas tão forte que leva à consolidação da perspectiva de que esses dois âmbitos são diametralmente opostos, isto é, essa "figura humana" não faria parte da "natureza", ao menos o humano que possui profunda relação com o natural, sem o anteparo da tecnologia.

A negação dessa natureza, e do sertanejo real, no âmbito agrícola, evidencia-se com a implantação do pacote da revolução verde, uso de defensivos químicos e técnicas oriundas de países de clima temperado, a serviço da "expansão da fronteira agrícola", sob os PNDs - Programas Nacionais de Desenvolvimento.

Além de técnicas e insumos importados, foi reativada uma concepção ideal de paisagem, referenciada a partir de sociedades e países europeus e dos EUA, com a inserção de imagens na mídia, escrita, falada e televisiva, alterando-se o panorama acerca da natureza. Esta deixa de ser hostil e inóspita, e caminha para a idealização, com o retorno das imagens medievais e da colonização, que a consideravam exuberante e exótica, mas que, agora, precisava ser moldada de acordo com as paisagens de clima temperado.

A midiatização da natureza foi, e é, relevante, porquanto a televisão principal meio de comunicação no Brasil - gere um laço social, mesmo que frágil, fundado na confiança do público de que o meio televisivo apresentará aquilo que existe de mais interessante e importante, oferecendo uma seleção mais coerente das grandes questões do momento (WOLTON, 1996).

Confiança essa alicerçada no modelo de promessa (JOST, 2004), em que parte-se do pressuposto de que cada programa carrega em si uma promessa ontológica. Cada gênero deveria apresentar aquilo a que se propõe: a comédia deve fazer rir e o drama deve fazer chorar, caso contrário perdem sua força e o público pode se desligar de tais atrações.

De forma que, o laço social televisivo altera a nossa perspectiva da natureza, no entanto reproduz os signos do determinismo ecológico dual e, por 
conseguinte, da dominação colonial. Na mídia, a natureza é idealizada como exuberante e exótica, mas separada do humano, ser não natural, ou ao menos, criação diferenciada.

A construção idealizada do "natural" se constitui em campo fértil na sociedade brasileira em função do caráter de verossimilhança que as imagens televisivas carregam, fundamentada na gramática da persuasão (ROCCO, 2003). Essa gramática constrói mensagens calcadas quase sempre no plausível, no provável, no emotivo e no afetivo, tornando possível convencer os telespectadores a consumir, embora a recepção não possa ser padronizada, pois os indivíduos são diferentes e respondem de forma diversa aos estímulos da televisão.

Essa mensagem é, contudo, fundamentada em dois sistemas básicos de comunicação: os signos e os clichês (MARCONDES FILHO, 1988). Os signos são uma representação neutralizada de ações, pessoas, objetos, situações, acontecimentos, o mundo real. $E$ os clichês são os momentos de entrega à emoção, em que o telespectador relembra inconscientemente emoções passadas, que, agora, permanecem mentais, platônicas. Assim, os clichês são símbolos tradicionais de amor, família feliz, com os quais as pessoas se identificam, porém que não se aproximam da experiência real visto serem imagens ou esquemas tradicionais.

Diante disso, indaga-se até que ponto as mensagens televisivas são, como afirma Rocco (2003), baseadas no verossímil, no plausível e no provável, posto que são representações iconográficas, mas que para Debray (1993), seriam a materialização do real, em que o mundo só passaria a existir quando visto, ou seja, no momento que se apresentasse como imagem para o deleite dos olhos.

A existência do real por meio da imagem é problemática porquanto possa sofrer distorção, já que a tecnologia acaba domesticando a imagem, retirando-Ihe o "dom capital de consolidar a comunidade crente", função que a imagem carrega, pois "[...] não há massas organizadas sem suportes visuais de adesão. Cruz, Pastor. Bandeira vermelha, Marianne." (DEBRAY, 1993, p. 91); 
isto porque, o visual atua com poder demonstrativo, tornam palpáveis os ideais, os objetivos, as crenças ou ideologias, influenciando sem necessidade de tradutores, de concentração ou desenvolvimento de raciocínio.

Toda essa facilidade trazida pela imagem e sua disseminação através, particularmente, da televisão nos coloca dentro da videosfera, ou a era do visual (DEBRAY, 1993). Nessa videosfera se prima pela rapidez, pela mudança acelerada, pelo consumo e pela construção de estereótipos, ou seja, imagenssímbolo, que coadunam com a ideia de clichê, visto que ambas trabalham sob a lógica de manutenção das estruturas tradicionais, por se constituírem em modelos, seja de comportamento ou atitudes. Até a subjetividade é mercantilizada, transformada em imagem, porém, "[...] uma imagem previsível, pouco problemática, livre de risco e ambiguidade, reduzida à sua força informacional centrípeta: um estereótipo, um clichê, portanto." (BRASIL, 2006, p. 92).

Por essa razão, construir imagem não seria somente representar o real, mas construí-lo, sob o ponto de vista de um discurso estandardizado, sobretudo no caso da televisão, que funciona "[...] mais pelo dever do que pelo ver, assume o dever de fazer-nos ver tudo o que importa. Encarna o julgamento da sociedade." (DEBRAY, 1993, p.312).

Desse modo, a prerrogativa da imagem de construir o real acaba colocando em crise a própria noção de representação, pois agora, a imagem impõe-se, segundo Gruzinsky (2006, p.301), como única e obsessiva realidade, retransmitindo uma ordem visual e social e comunicando modelos de comportamento e crenças, como que encarnando um “'[...] religioso difuso', dissolvido no consumo, destilando no cotidiano a insignificância de seus milagres, exibindo os paraísos de uma presença imediata, de uma imanência impalpável.".

Entretanto, essa perspectiva da imagem está intrinsecamente associada ao sujeito que pronuncia um determinado enunciado, pois é esta enunciação que se constitui em realidade. Em outras palavras, quer-se dizer que a realidade não pode ser julgada pela comparação entre ela e o que é 
transmitido, "[...] mas pelo reenvio que o enunciado faz a um sujeito real." (JOST, 2004, p. 117). Isto confere ainda maior responsabilidade para o sujeito, pois ele é posto também na ideia de construção da realidade por meio da imagem ou do texto.

Essa perspectiva demonstra não só a relevância da imagem, mas, a um só tempo, que se, a natureza iconográfica produzida pelos meios de comunicação é percebida como "lindos jardins", isso se refere não apenas à ação da mídia, por meio de seus instrumentais, mas a uma atitude humana que ratifica tal noção. Essa perspectiva da natureza só se apresenta com grande efetividade porque o sujeito real a reenvia, reproduzindo tal enunciado, o que nos é muito caro para pensar o ser brasileiro e a representação de natureza.

\section{CONSIDERAÇÕES FINAIS}

Esse caminhar panorâmico na história de formação do Brasil, ainda que an passant, revelou questões de longa data acerca da ideia de natureza atuando como fatores limitantes sobre a formação social brasileira. Observa-se que a representação predominante da natureza se refere à dicotomia dominador-dominado, e no determinismo ecológico dual, originados no contexto colonial. Nessa perspectiva, o meio natural seria um bem a ser usufruído e utilizado sem freios pelo "descobridor" europeu, já que se constituiria em um elemento inesgotável a serviço do dominador.

Sob um duplo modus operandi do determinismo ecológico dual, a dominação colonial, de um lado, se projetava sobre a natureza como um inferno verde, limitante ao desenvolvimento de sociedades. De outro, justificava sua ações exploratórias a partir da ideia de paraíso provedor inesgotável de riquezas.

Nos séculos iniciais da formação social brasileira, a natureza foi representada como um bem a ser utilizado, e simultaneamente, estigmatizada sob a ideia aristotélica de "inferno verde" tropical limitante, a ser (re)apropriado e domesticado. Essas premissas do determinismo ecológico dual, convertidas em "destino ecológico", foram apropriadas e postas a serviço da dominação colonial. Outrora coercitiva, no século e década recente a dominação colonial 
LOIOLA, S. A.; CARDOSO, L. S.; ARAÚJO, A. M.; NAZARENO, E.

DA DOMINAÇÃO COLONIAL A COLONIALIDADE DO SABER: EFEITOS DO DETERMINISMO

ECOLÓGICO DUAL SOBRE A FORMAÇÃO SOCIAL BRASILEIRA

foi internalizada pelo pensamento, cedendo lugar a colonialidade do saber. As influencias do determinismo ecológico dual perpassaram desde período colonial e perduram, engendradas por interesses econômicos, sociais, culturais e, por fim, midiáticos, relacionados ao consumo, a ideia de desenvolvimento na perspectiva de países do "norte", à construção da nacionalidade e do próprio Estado brasileiro.

Todos esses aspectos expõe que a representação da natureza é essencial para se pensar o "ser brasileiro". Os estigmas dessa representação evidenciam-se na figura do Jeca Tatu, ainda hoje presentes no Brasil. Um personagem que leva ao riso, o qual representa uma punição por simbolizar um desvio, mas que pode ser, ao mesmo tempo, um dos símbolos do brasileiro "real", ligado ao espaço e à natureza. Dicotomia que catalisa signos do determinismo ecológico dual: natureza exuberante ou inferno verde limitante, e, a um só tempo, inferioriza os elementos formadores da sociedade brasileira, sobretudo indígenas e negros. Expondo igualmente o alcance da Teoria do degeneracionismo sobre as etnias e lugares na formação de muitas nações latino-americanas.

Tal realidade foi significativa na exclusão de indígenas e negros no processo de construção da nacionalidade em grande parte da história, já que a partir da Constituição de 1988 se reconheceu o caráter diverso da sociedade nacional. Até então essas parcelas eram inferiorizadas em relação aos de origem europeia, ainda que se reconheça a atenção do Estado ao indígena, com a estruturação do Serviço de Proteção ao Índio, em 1910, depois FUNAI (a partir de 1967).

Entende-se que essas sociedades eram inferiorizadas por suas composições físicas, suas formas de vida, de pensar, de sentir, de ser. Assim, a representação de indígenas e negros como inferiores foi naturalizada. No caso dos primeiros, a representação como inferior era reforçada também por sua estreita relação com a natureza. Esta natureza, representada pelo dualismo paraíso-inferno sob as premissas do determinismo ecológico, era vista por linhas abissais que separavam a humanidade do meio natural. 
Associado ao meio natural, o indígena foi considerado um ser aquém do humano.

A partir desse processo segregador e violento, o Estado brasileiro forjou a nação, excluindo a maioria de sua sociedade, invisibilizando a relação do homem com a natureza e o espaço natural. Porque a escolha desse caminho? Se uma sociedade vive próxima à natureza ou integrada a ela, por que se apartar?

A reprodução do desejo de dominação, de signos pejorativos, os conflitos e a degradação ambiental sugerem que o determinismo ecológico dual perdura, afastando a sociedade de um mundo de possibilidades social e ecológicos diversos. Não estaria na hora de romper com os laços de dominação, contidos nas ideias deterministas de destino ecológico, e fazer as pazes com, e entre, o meio ecológico e a diversidade sociocultural? Essas questões convidam a novas reflexões, pesquisas e ações, em especial, na direção de uma ecologia de saberes.

\section{REFERÊNCIAS BIBLIOGRÁFICAS}

ALBERTI, V.. O riso e o risível na história pensamento. Rio de Janeiro: Jorge Zahar Ed., 2002. (Coleção antropologia social).

ALENCAR, José de. O sertanejo. São Paulo: Ática, 1995 (1875).

APOLINÁRIO, J. R.. Os Akroá e outros povos indígenas nas fronteiras do Sertão - política indígena e indigenista no norte da capitania de Goiás Século XVIII. Goiânia: Kelps, 2006.

ARAÚJO, A. M. de. Cadê a água que estava aqui? Os leitos secos na memória e na história. História Revista, Goiânia, № 15, p.1-20, 2009.

BERGSON, H. O riso: ensaio sobre a significação do cômico. Rio de Janeiro: Zahar, 2001. 
BENAVIDES, O. H.. Retornando à origem: Arqueologia Social como filosofia latino-americana. Tradução. Revista Terceiro Incluído, Goiânia, v. 1, n. 2, p. 164-192, 2011.

BOSI, A.. Dialética da colonização. São Paulo: Companhia das Letras, 2002.

BRASIL, A.. Entre ver e não ver: o gesto do prestidigitador. In: GUIMARÃES, C.; LEAL, B. S.; MENDONÇA, C. C. (Orgs.). Comunicação e experiência estética. Belo Horizonte: Editora UFMG, 2006. p. 88 - 102.

CAPRA, F.. A teia da vida. São Paulo: Cultrix, 2001.

CARVALHO, J. M. de. A formação das almas: o imaginário da república no Brasil. São Paulo: Companhia das letras, 1990.

CUNHA, Euclides da. Os sertões: campanha de Canudos. Rio de Janeiro: Laemmert, 1902

DEAN, W..A ferro e fogo: a historia e a devastação da Mata Atlântica brasileira.São Paulo: Cia das Letras, 1996.

DEBRAY, R.. Vida e morte da imagem: uma história do olhar no ocidente. Tradução de Guilherme Teixeira. Petrópolis - R.J.: Vozes, 1993.

DOLES, D. E. M.; NUNES, H. P.. Memória da ocupação e colonização de Goiás na primeira metade do século XIX: A visão dos viajantes europeus. Ciências humanas em Revista, Goiânia, v.3, n.1/2, p. 71-118, 1992. 
DUSSEL, E.. Meditaciones anti-cartesianas: sobre El origen Del anti-discurso filosófico de la Modernidad. Tabula Rasa, Bogotá -Colombia, n. 9, p. 153-197, 2008.

FUNARI, P. P.; NOELLI, F. S.. Pré-história do Brasil. São Paulo: Contexto, 2002.

GIUCCI, G.. Viajantes do Maravilhoso. O novo mundo. São Paulo: Cia das Letras, 1992.

GONÇALVES, C. W. P.. Os (des) caminhos do meio ambiente. São Paulo: Contexto, 2002.

GRUZINSKY, S.. A guerra das imagens: de Cristovão Colombo a Blade Runner (1492-2019). Tradução de Rosa Freire d'Aguiar. São Paulo: Companhia das Letras, 2006.

GUIMARÃES, M. L. S.. Nação e civilização nos trópicos: O instituto histórico e geográfico brasileiro e o projeto de uma história nacional. Estudos Históricos, Rio de Janeiro, n. 1, p. 5-27, 1988.

HISSA, C. E. V.. A mobilidade das fronteiras: inserções da geografia na crise da modernidade. Belo Horizonte: Editora UFMG, 2002.

IANNI, O.. Tipos e mitos do pensamento brasileiro. Sociologias, Porto Alegre, ano 4, no 7 ,p. $176-187,2002$,

JOST, F.. Seis lições sobre a televisão. Porto Alegre: Sulina, 2004.

LADOUCEUR, M.. Índios e negros na geografia brasileira. Boletim de geografia teorética, Rio de Janeiro, v. 22, p. 417-423, 1992. 
LARAIA, R. de B.. Cultura: um conceito antropológico. Rio de Janeiro: Jorge Zahar Ed., 2002.

LEFF, E.. Construindo a História Ambiental da América Latina. ESBOÇO Revista do Programa de Pós-Graduação em História da UFSC, Florianópolis, n. 13, p. 11-26, 2005.

LIMA, N. T.. Um sertão chamado Brasil: intelectuais e representação geográfica da identidade nacional. Rio de Janeiro: Revan: IUPERJ, UCAM, 1999.

LISBOA, K. M. A natureza brasileira no olhar de dois naturalistas alemães. In.: CONGRESSO INTERNACIONAL AMÉRICA 92: RAÍZES E TRAJETÓRIAS. AMÉRICA LATINA: IMAGENS, IMAGINAÇÃO E IMAGINÁRIO, Rio de Janeiro, São Paulo, Expressão e Cultura/Edusp, v. 8, 1997, p. 421-434.

LITTLE, P. E.. Territórios sociais e povos tradicionais no Brasil: por uma antropologia da territorialidade. Brasília: UNB, 2002. 31 p. (Antropologia). Mimeo.

LOBATO, José Bento Monteiro. Urupês. Globo Livros, 2007 (1918).

LOIOLA, S. A.; RATTS, A. J. P.. Discursos pós-modernos e o enfoque das fronteiras na geografia. In: XIV ENCONTRO NACIONAL DE GEÓGRAFOS, 2006, Rio Branco. A Geografia e a Amazônia no contexto latino americano: diálogos, práticas e percursos, 2006. Cd-Rom.

LORENZ, K..A demolição do homem: Crítica à falsa religião do progresso. Tradução Horst Wertig. São Paulo: Brasiliense, 1986. 
MARCONDES FILHO, C.. Televisão: a vida pelo vídeo. São Paulo: Moderna, 1988. (Coleção Polêmica).

MARTINS, M. L.. História Ambiental: suportes teórico-metodológicos. In: História e Meio Ambiente. São Paulo: Annablume: Faculdade Pedro Leopoldo, 2007. p. 33-72

MEGGERS. B.. América pré-histórica. São Paulo: Paz e Terra, 1979.

MIGNOLO, W.. El lado más oscuro Del Renacimento. Universitas humanísticas, Bogotá - Colômbia, n. 67, p.165-203, 2009.

PRESTES, M. E. B.. A investigação da natureza no Brasil colônia. São Paulo: Annablume: FAPESP, 2000.

PROUS, A.. O Brasil antes dos brasileiros: a pré-história de nosso país. Rio de janeiro: Jorge Zahar, 2006.

QUIJANO, A.. Colonialidade do Poder, Eurocentrismo e América Latina.In: EDGARDO LANDER (Org.). A colonialidade do saber: eurocentrismo e ciências sociais. Perspectivas latino-americanas. Colección Sur Sur, CLACSO, Buenos Aires - Argentina, setembro 2005. p. 227-278.

RAFFESTIN, C. Por Uma Geografia do Poder. São Paulo: Ática, 1993.

RATTS, A. J. P.. A Geografia entre as aldeias e os quilombos: territórios etnicamente diferenciados. In: ALMEIDA, M. G; RATTS, A. J. P. (Orgs.). Geografia: leituras culturais. Goiânia: Alternativa, 2003. p.29-48.

.Fronteiras invisíveis: Territórios negros e indígenas no Ceará. Dissertação (Mestrado em geografia) - Departamento de Geografia da 
Faculdade de Filosofia, Letras e Ciências Humanas. Universidade de São Paulo, 1996.

ROCCO, M. T. F. Linguagem autoritária: televisão e persuasão. São Paulo: Brasiliense, 2003. (Comunicação \& Informática).

ROQUETTE-PINTO, E.. Seixos Rolados: estudos brasileiros. Rio de Janeiro: Mendonça, Machado \& Companhia, 1927.

SAINT-HILAIRE, A. de. Viagem a Província de Goiás. Tradução: Regina Regis Junqueira. Belo Horizonte: Itatiaia; São Paulo: Ed. da USP, 1975.

SANTOS, B. de S.. Para Alem do Pensamento Abissal: das linhas globais a uma ecologia dos saberes. In: SANTOS, B. de S.; MENESES, M. P.. Epistemologia do Sul. Coimbra-PT: Editora Almedina, Coleção CES: 2009. p. 31-83.

. Entre Próspero e Caliban: Colonialismo, Pós-Colonialismo e InterIdentidade. In:

A gramática do tempo: para uma nova cultura política. São Paulo: Cortez, 2006. Capítulo 7, p. 227 - 276. (Coleção para um novo senso comum; v. 4).

SEEMANN, J.. Mapeando culturas e espaços: uma revisão para a geografia cultural no Brasil. In: ALMEIDA, M. G.; RATTS, A. J. P. (Orgs.). Geografia: leituras culturais. Goiânia: Alternativa, 2003. p.261-284.

SOUZA, M. L. de. A expulsão do paraíso. O "paradigma da complexidade" e o desenvolvimento socioespacial. In: CASTRO, I, E.; GOMES, P, C. da C.; CORREA, R. L. (Orgs.). Explorações Geográficas: percursos no fim do século. Rio de Janeiro: Bertrand Brasil, 1997, p.43-87.

STEWART, J.H..Culture areas of the tropical forests. Handbook of the south American indians, v. 3, n. 143, p. 883-899, 1963. 
TEIXEIRA, Dante Martins \& PAPAVERO, Nelson. Os primeiros documentos sobre a história natural do Brasil (1500-1511): viagens de Pinzón, Cabral, Vespucci, Albuquerque, do Capitão de Gonneville e da Nau Bretoa. Belem: Museu Paraense Emílio Goeldi, 2002.

TODOROV, T.. A conquista da América: a questão do outro. Tradução de Beatriz Perrone Moisés. São Paulo: Martins Fontes, 1983.

WOLTON, D.. Elogio do grande público: uma teoria crítica da televisão. Tradução de José Rubens Siqueira. São Paulo: Ática, 1996. (Temas; v. 52).

WORSTER, D.. Para fazer História Ambiental. Estudos Históricos, Rio de Janeiro, v..4, n. 8, p.198-215, 1991. 